Erschienen in: Poznan Studies in Contemporary Linguistics ; 53 (2017), 1. - S. 63-93 https://dx.doi.org/10.1515/psicl-2017-0004

\title{
SOMETHING ALWAYS STICKS? HOW EMOTIONAL LANGUAGE MODULATES NEURAL PROCESSES INVOLVED IN FACE ENCODING AND RECOGNITION MEMORY
}

\author{
JOHANNA KISSLER \\ University of Bielefeld \\ johanna.kissler@uni-bielefeld.de
}

\author{
JANINE STREHLOW \\ University of Konstanz \\ janine.strehlow@uni-konstanz.de
}

\begin{abstract}
Language can serve to constrain cognitive and emotional representations. Here, we investigate to what extent linguistic emotional information alters processing of faces with neutral expressions. Previous studies have shown that cortical processing of emotional faces differs from that of neutral faces. Electroencephalography (EEG) has revealed emotion effects for early and late event-related potentials (ERPs) such as the N1, the Early Posterior Negativity (EPN) and the Late Positive Potential (LPP). In order to study the effect of language information on face processing, 30 negative and 30 neutral descriptive phrases were presented, each followed by a neutral expression face. Participants were instructed to remember the association. We analyzed the immediate effect of information type on face processing during encoding as well as delayed effects during subsequent recognition. During encoding, faces following negative language information elicited a larger left frontal positivity between 500-700 ms after stimulus onset. During recognition, a left centro-parietal LPP was likewise increased for faces previously associated with a negative description. In addition, the parietal old/new effect was significantly increased for faces with negative information compared to new ones, while no significant effect was observed for faces with neutral information. No information effects on early perceptual ERPs (N1, EPN) were found. Reaction times (RTs) for source memory decisions (negative versus neutral) were significantly shorter for faces with negative versus neutral information. In sum, ERP results indicate that emotional significance can be linguistically induced in faces on a cortical level and, at least in an explicit memory task, this information modulates later stages of face processing and memory. Implications for cognitive effects of public media design are discussed.
\end{abstract}

KEYWORDS: Emotion; language; faces; perception; memory; EEG. 


\section{Introduction}

Language has been suggested to construct and constrain emotion (Barrett et al. 2007). In the present study, we aim to investigate to what extent preceding linguistic information can imbue emotional significance on neutral faces similar to the effects of emotional face expression on face processing and whether this is reflected in recognition memory performance. To motivate our study, we first outline current knowledge regarding emotional face perception and memory as well as memory in emotional contexts. Against this background, we address the role of language as a means of emotional appraisal, further motivating the current study using prior linguistic information as emotional context for face perception and memory.

\subsection{Emotional face perception}

Facial expression is a powerful non-verbal communication channel that humans automatically orient to. EEG experiments confirm that emotional faces are processed preferentially (Eimer et al. 2007; Schupp et al. 2004b). This is evident for early and late event-related potentials (ERPs), starting with emotional N1/N170 effects. The face-sensitive N1 appears between 100-200 ms after stimulus onset over occipital brain areas. It has been reported to already exhibit higher amplitudes to emotional faces (Blau et al. 2007). Following the N1, the early posterior negativity (EPN), a relative negativity for emotional compared to neutral stimuli occurs between $200-300 \mathrm{~ms}$ at occipito-temporal sites. The EPN is increased for anxious or angry facial expressions compared to happy or neutral ones (Sato et al. 2001; Schupp et al. 2004b). Furthermore, during emotional face processing a late positive potential (LPP) appears over centro-parietal regions. Again, threatening angry faces appear to elicit particularly large LPPs (Schupp et al. 2004b). Similar emotion effects are also found for other types of stimuli such as words (Kissler et al. 2006, 2007, 2009), gestures (Flaisch et al. 2011), or pictures (Junghöfer et al. 2001; Schupp et al. 2004a). In general, early emotion effects in vision are thought to reflect emotionally motivated selective attention and perceptual tagging (Schupp et al. 2003, 2004b), whereas effects in the LPP window reflect explicit stimulus evaluation and memory processing (Schupp et al. 2003, 2004b). Emotion-LPPs can be functionally differentiated into an earlier P3a component, typically observed around $300 \mathrm{~ms}$, and a later P3b/LPP positive slow-wave, arising around $500 \mathrm{~ms}$. The P3a often has a more anterior topography, whereas the P3b/LPP displays a centro-parietal distribu- 
tion. Positive potentials in the P3a time-range appear to indicate attentional orienting towards emotional stimuli, whereas the P3b/LPP seems more related to evaluation and memory operations (Olofsson et al. 2008).

\subsection{Emotional memory}

Emotional events are often better remembered than neutral ones (e.g. Sharot and Phelps 2004) and emotional memories appear more vivid (Kensinger and Corkin 2003). Emotion benefits in memory can occur during encoding, during retrieval, or for both processing stages and they can take place automatically and incidentally. EEG data reveal that larger LPPs for emotional stimuli during emotional or semantic evaluation as incidental encoding tasks predict better subsequent recollection of these stimuli (Dolcos and Cabeza 2002; Weymar et al. 2013).

During recognition, an old/new effect is typically observed which is characterized by increased positive waveforms for old versus new stimuli, reflecting successful retrieval of information from long-term memory (Rugg et al. 2007). Two types of old/new effects are commonly found. An early frontal old/new difference between $300-500 \mathrm{~ms}$ seems to be based on stimulus familiarity. A later parietal old/new difference around $500 \mathrm{~ms}$ typically reflects explicit retrieval (Rugg et al. 2007; Weymar et al. 2009, 2013). Weymar et al. (2009) analyzed recognition memory for emotional and neutral pictures one week after encoding. They found enhanced late centro-parietal old/new effects for emotional pictures but no modulation by emotion for early frontal old/new effects. Topographically, the emotion enhancement for the late old/new effect was particularly pronounced over left centro-parietal sites. Schaefer and colleagues $(2009,2011)$ investigated the interaction between emotional intensity and recognition memory for pictures. Emotional modulation of the old/new effect was significant for the low and moderately emotional condition but not for high and extreme intensities (Schaefer et al. 2009). Furthermore, an emotion effect for the late parietal old/new effect (500-700 ms) was found only for items judged as remembered but not for those merely familiar. Finally, in Schaefer et al.'s studies (2009, 2011), the old/new effect was restricted to emotional items and practically absent for neutral ones.

Specifically regarding face memory, faces with negative expressions have been shown to induce larger old/new effects than positive or neutral ones (Johansson et al. 2004). Although behaviorally the old/new discrimination was not significantly modulated by emotion, the parietal ERP old/new effect was larger 
for negative faces (Johansson et al. 2004). Similarly, Righi and colleagues (2012) found increased old/new effects for faces encoded with a fearful expression. They presented faces with happy, fearful or neutral expressions during learning, while during recognition faces were presented with the same identity but a neutral expression, and found the parietal old/new effect to be increased for faces with initially fearful expressions (Righi et al. 2012). Notably, this study indicates a conceptual locus of the observed emotion effects, as effects persisted even when the physical feature configuration at test changed from negative to neutral.

\subsection{Emotional language as a context for memory}

Whereas the above studies demonstrate memory effects of intrinsically emotional stimuli, emotional contexts can also modulate processing of originally neutral material. Language, in particular, can provide such a conceptual context (Barrett et al. 2007). In two EEG experiments, Maratos and colleagues (2001a, 2001b) presented neutral words - first alone and then embedded in negative or neutral sentences - followed by an immediate old/new recognition test on the individual words. In the second experiment, the old/new decision was followed by a source memory test where participants had to decide further whether the encoding context for the "old" words had been negative or neutral. EEG results from the first experiment revealed an increased left parietal old/new effect as well as an additional right frontal old/new effect for words embedded in a negative context. In the second experiment, the left parietal and right frontal old/new effects were similar for words correctly assigned to their context regardless of context valence, but an additional late posterior old/new effect was specific for words within a negative context (Maratos et al. 2001a). Interestingly, despite neural emotion effects, recognition memory differed only marginally (Maratos et al. 2001a, 2001b). In a recent behavioral study, Mattarozzi and colleagues addressed the effect of linguistic context on affective evaluations and memory for faces (Mattarozzi et al. 2014). Participants viewed faces embedded in fake headlines of newspaper articles describing neutral, pleasant, or unpleasant actions of the depicted person. Faces were remembered better if perceived as trustworthy or untrustworthy rather than neutral, and recall of the associated valencecongruent contextual details expressed in the headline was enhanced (Mattarozzi et al. 2014). 
Abdel Rahman (2011) studied the effects of simultaneously presented auditory emotional biographic information on recognition of famous versus initially unknown faces. Emotionally salient information about famous faces was refreshed or newly established for unknown faces. Two to three days after such context-learning, participants had to perform an old/new recognition test and indicate the nationalities and proper names of the presented faces while their EEG was recorded. Context effects on LPP amplitudes were found for both wellknown and unfamiliar faces. Stimuli paired with emotionally salient biographies elicited larger LPPs than stimuli associated with neutral ones. For well-known faces embedded in emotional context, a larger EPN was also found, but this could have been a pre-existing difference. The results suggest that emotional language information - when presented simultaneously with a face - can modulate cortical face processing at mid-latency (EPN) and late (LPP) processing stages several days after information presentation, the pattern depending on the initial familiarity of the faces. Behaviorally, valence of information affected sympathy ratings and reaction times on a famous/non-famous decision task. Reaction times were faster for faces with negative versus neutral context and negative versus positive stimulus information. Memory accuracy was not reported (Abdel Rahman 2011). Thus, overall, simultaneously presented emotional language context can modulate memory processing of neutral stimuli in a way similar to that of intrinsic emotional significance.

\subsection{Language as a means of emotional appraisal}

In everyday life, descriptive language is a very common form of social information transmission and an important pragmatic function of language (Bühler 1934). Language not only modulates the processing of concurrently presented stimuli, but may also change the way humans process stimuli following linguistic information, including early stages (N1) of face perception (Landau et al. 2010; Righart and de Gelder 2005). Its impact is evident in gossip and the media, where we often learn about other people before actually meeting them or even without ever meeting them. Accordingly, some scientific studies have already investigated emotional language as a means of emotion regulation and appraisal. For instance, MacNamara and colleagues examined how auditory language information modulates the subsequent electro-cortical processing of affective pictures (MacNamara et al. 2009, 2011). Negative or neutral audiodescriptions preceded unpleasant and neutral pictures from the International Affective Picture System (IAPS). A sequence of parieto-occipital and central posi- 
tivities (between 300-400 ms, around $500 \mathrm{~ms}$, and after $700 \mathrm{~ms}$ ) exhibited larger amplitudes for negative versus neutral pictures when preceded by negative rather than neutral descriptions. Affect-congruent changes in valence and arousal ratings were also found (MacNamara et al. 2009). The main effects persisted after a thirty minute delay (MacNamara et al. 2011), indicating immediate and delayed effects of preceding language information on picture appraisal. Another recent study employed stimuli that varied in terms of emotional valence and viewer-relevance of a descriptive phrase preceding a face. Face-evoked EPN and LPP were larger both when the preceding text related to the participant and when it contained a negative statement (Wieser et al. 2014). Finally, in an evaluative conditioning procedure, we recently presented male faces together with auditory descriptions of criminal or occupational activities and, upon immediate repeated presentation of the faces, found enhanced mid-latency (EPN-like) magnetoencephaolgraphic responses and more negative valence ratings for the negatively paired faces (Junghöfer et al. 2016).

In sum, extant results demonstrate that both preceding and concurrent language information can directly shape some aspects of scene (McNamara et al. 2009) and face perception (Junghöfer et al. 2016; Landau et al. 2010; Wieser et al. 2014). Electrophysiological effects have been documented at early (Landau et al. 2010; Righart et al. 2005), mid-latency (Abdel Rahman 2011; Junghöfer et al. 2016; Wieser et al. 2014), and late processing stages (Abdel Rahman 2011; McNamara 2009, 2011; Wieser et al. 2014). Moreover, memory effects of linguistic emotional contexts have been documented on the neural (Abdel Rahman 2011; Maratos et al. 2001a, 2001b; McNamara et al. 2011) and on the behavioral level (Mattarozzi et al. 2014), although not all neural effects are reflected in explicit memory effects (Johansson et al. 2004; Maratos et al. 2001a, 2001b).

\subsection{The current study}

Based on the above findings, we investigate the effect of preceding emotional language information on both immediate processing and subsequent memory for novel neutral faces in an explicit recognition memory design. We use short linguistic phrases describing an immediately following target face as neutral via occupational status or as negative via descriptions of criminal activities signaling threat. We test whether emotional information affects face recognition behaviorally, as reflected in response rates or reaction times. On the neural level, we expect that information about criminal background versus neutral occupation will amplify brain activity, both during context - face association during encod- 
ing, and also during subsequent face recognition. We examine the processing stages (N1, EPN and LPP) at which effects may occur. In terms of old/new comparisons, we expect stronger cortical activation for old versus new stimuli during late processing stages (parietal old/new effect). Assuming an additional emotion benefit, old faces with negative information should elicit stronger activation than either faces with neutral information or new faces.

\section{Methods}

\subsection{Participants}

Data were collected from 24 healthy right-handed students (mean age 21.96, 12 male and 12 female) at the University of Konstanz, Germany. Participants provided informed consent. They received course credit or 10 Euros per person as expense allowance. The sample size was determined in accordance with our previous experience with EEG experiments on emotional stimulus processing. In previous studies of emotion language processing using similar materials, we tested 16 participants ( 8 male and 8 female), achieving medium-sized to large effects (Kissler et al. 2007). Since we used affective language only as a descriptor for faces and expected smaller effects here, we expanded the previous sample size by $50 \%$. A recently published evaluative conditioning study using the same materials tested 21 participants (Junghöfer et al. 2016). To avoid gender-specific influences, 12 healthy female and 12 healthy male participants were recruited.

\subsection{Stimuli}

Faces: A black and white picture set of 120 neutral male faces was used. The pictures were taken from Aberdeen, Nottingham Scans, Karolinska Institutet Emotion Lab (KDEF) and NimStim (Tottenham et al. 2009) face sets as available from the authors or from the Internet. All pictures showed neutral face expression and were processed via Photoshop CS 4 to match brightness and photo size. All the pictures showed faces of young males in full view with shut mouth, short hair, no beard and no glasses.

Language descriptors: Emotionally charged sentences were constructed using negative and neutral adjectives and nouns referring either to crimes (murderer, rapist, etc.) or occupations (gardener, carpenter, etc.). The adjectives were 
selected from a pre-existing in-house database containing ratings obtained using a nine-step self-assessment manikin (SAM) scales with 1 indicating highly negative, 5 - neutral, and 9 - highly positive valence (see also e.g. Kissler et al. 2007, 2009; Herbert et al. 2008, 2009). Word frequency per one million written words was determined according to CELEX (Baayen, Piepenbrock et al. 1995).

Negative adjectives had 152.2 mean word frequency and 2.39 mean valence (ranging from 1.83 to 2.85). In comparison, neutral adjectives had an average frequency of 183.53 and 5.05 mean valence (ranging from 4.31 to 5.94). The adjectives' valence ratings differed significantly between negative and neutral adjectives $[F(1,58)=596.050 ; p<0.001]$, while their mean frequencies did not differ $[F(1,58)=1.008 ; p=0.320]$. In addition, occupation terms with 378.27 mean frequency and criminal terms with 369.07 mean frequency were selected. These frequencies did not differ significantly $[F(1,58)=0.019 ; p=0.890]$.

At the time of this experiment, we relied on individual word ratings to construct the sentences and focused on valence ratings, relying on the typical natural co-variation of valence and arousal. However, in the meantime an additional experiment using this material has been conducted (Junghöfer et al. 2016), where individual participants' ratings of the whole sentences were obtained preexperimentally from 21 individuals. These sentence ratings confirmed differences for valence and arousal of the full sentences: crime sentences were rated as more negative $[t(20)=-15.45, p<.001]$, and more arousing $[t(20)=-9.89$, $p<.001]$ than occupation sentences. The sentences used are listed in Appendix 1 (both the original and translated versions).

\subsection{Design and procedure}

Overall, the experiment consisted of three experimental phases. First, during the baseline phase, faces were presented individually. Second, during the encoding phase, faces were preceded by descriptive phrases and memorization instructions were given. During the encoding phase, each sentence - face pair was repeated twice in order to improve encoding. Finally, during the third phase, an old/new recognition test followed.

Faces were randomly assigned to the negative (30x) or neutral condition (30x), or served as distractors during a subsequent recognition test $(60 \mathrm{x})$. Each face was preceded by a descriptive phrase about the person's supposed occupation (neutral) or criminal activities (negative). The design of the experiment is illustrated in Figure 1. 


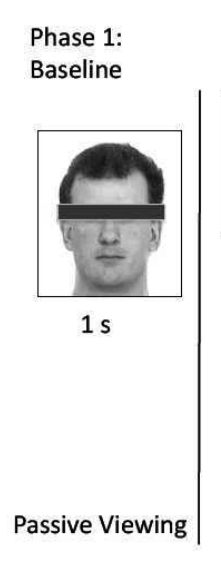

Phase 2: Encoding

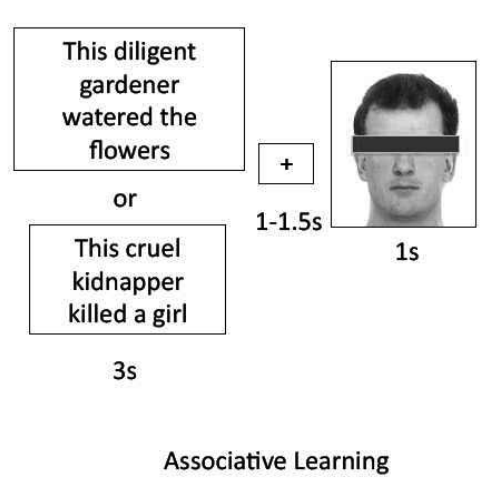

Phase 3:

Recognition Test:

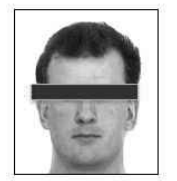

1s

a) Old/New?

b) Source:

Crime or Job

Figure 1. Outline of the experimental design consisting of three phases: first, a passive viewing phase (left), second, an encoding phase where an association between a descriptive phrase and a subsequently presented face had to be formed (middle), and third, a recognition phase consisting of a two-step test (old/new; source) shown on the left. The faces were always presented for $1 \mathrm{~s}$, the description in phase 2 was presented for $3 \mathrm{~s}$, and interstimulus intervals, during which a fixation cross was presented, varied in all phases from 1 to $1.5 \mathrm{~s}$. To protect the depicted individual's privacy, the eye region is covered in this illustration.

Baseline Phase: In the baseline phase, participants viewed 60 neutral male faces presented for $1000 \mathrm{~ms}$ each with an interstimulus interval randomly varying between 1000-1500 ms. During the interstimulus interval a fixation cross was presented.

Encoding Phase: For the subsequent encoding phase, participants were instructed to explicitly memorize each sentence in association with the following face. Emotional language information was presented for $3000 \mathrm{~ms}$ prior to each face, providing enough time for reading and full understanding. As in the baseline phase, the faces were presented for $1000 \mathrm{~ms}$ and an interstimulus fixation cross was presented for 1000-1500 ms. Two differently randomized sequences of the information - face pairs were presented to facilitate encoding. The two sequences within the encoding phase were not coded separately, thereby precluding analysis of repetition effects within the encoding phase.

Recognition Phase: In the third and final recognition phase, the original faces were presented again and randomly mixed with 60 new faces serving as 
distractor items. As in the previous phases, during recognition old and new stimuli were presented for $1000 \mathrm{~ms}$ each. Participants were asked to perform an old/new recognition test. For faces classified as old, they had to decide further if the depicted person had been preceded by neutral (occupational) or negative (criminal) information. Participants were instructed to press the respective button after picture offset. Immediately thereafter, they were likewise cued to decide via a button press on the type of association (criminal or occupational). The next trial started 1000 to $1500 \mathrm{~ms}$ after the second response had been registered. Motor potentials were reduced to a minimum via using left and right buttons of a centrally presented mouse. Response-button assignment was counterbalanced across participants, who were instructed to keep their response hand on the mouse. The experiment was run via Presentation 10.2 (Neurobehavioral Systems, Albany, USA).

\subsection{EEG recording}

EEG was recorded via EGI HydroCel sensor nets with 256 electrodes plus reference using Net Station software. Data were acquired with $250 \mathrm{~Hz}$ sample rate and filtered online with $0.1 \mathrm{~Hz}$ high pass and $100 \mathrm{~Hz}$ low pass. 256 electrodes were referenced to $\mathrm{Cz}$ (channel 257) and impedances were kept below $30 \mathrm{k} \Omega$ during recording, as recommended by Electrical Geodesics, the manufacturer of this type of high-impedance amplifier (see also Ferree et al. 2001).

\subsection{Data analysis}

Recorded EEG data were preprocessed offline using BESA research 5.3 (Brain Electrical Source Analysis, MEGIS Software GmbH, Gräfelfing, Germany). Data were re-referenced to average reference and corrected for eye blinks using the topographic correction algorithm implemented in BESA (Ille et al. 2002). Remaining artifacts were rejected individually whenever necessary. Artifactcorrected data were band-pass filtered from 0.1 to $30 \mathrm{~Hz}$ and split into epochs from -100 to $1000 \mathrm{~ms}$ to analyze stimulus-evoked neural activity. The data were topographically visualized and statistically analyzed using EMEGS 2.4 (ElectroMagnetic EncephaloGraphy Software, <http://www.emegs.de>, Junghöfer and Peyk 2004). 


\subsection{Statistical analysis}

\subsubsection{Overview}

Calculations of recognition performance were performed with Statistica 9 (StatSoft, Inc. 2008). An alpha level of 0.05 was used for all electrophysiologi$\mathrm{cal}$ and behavioral calculations. Statistical analysis of EEG data was performed using MATLAB 7.11 and EMEGS 2.4 (Junghöfer and Peyk 2004). Based on the above outlined theoretical considerations derived from the literature, the analysis focused on N1, EPN, LPP, and old/new effects. Time windows of interest were identified on the basis of the root mean square (RMS) of face-evoked brain activity across all electrodes. Several sensor groups of interest were created based on visual inspection of difference topographies in the previously identified time windows of interest (see also Weymar et al. 2009, 2013 for a similar approach).

\subsubsection{Recognition performance}

Recognition performance was analyzed via paired t-tests comparing hits and false alarms for faces associated with negative versus neutral information. Separate paired t-tests were calculated after the first decision between old and new faces and after the second decision. In addition, reaction times were analyzed via calculating paired t-tests for hits and false alarms, analogously to recognition performance.

\subsubsection{EEG Data}

Sensor groups covering differences in ERP components were selected for the N1 (150-200 ms) and EPN (200-300 ms) at occipital sites (16 left and 16 right electrodes), and for a bilateral frontal and centro-parietal positivity effect during encoding (15 left and 15 right frontal and 18 left and right central electrodes) between 500 and $700 \mathrm{~ms}$. The centro-parietal sensor groups were also used to compare activity during recognition and baseline. For the early old/new effect (300-400 ms), two lateral frontal sensor groups were used (16 electrodes each), and for the late old/new effect (450-600 ms), a large occipito-parietal sensor group (55 electrodes) was selected. Selected channel groups are shown in Figure 2. RMS plots for each experimental condition are shown in Figure 3 for en- 
coding versus baseline, in Figure 5 for recognition versus baseline, and in Figure 7 for the old/new effect. For each ERP component, statistical comparisons addressed the effect of information content (negative or neutral) and phase on average activity at individual sensor groups and ERP components. Where bilateral sensor groups were used, laterality was used as an additional within-factor. ERP components were quantified as average areas under the curve for a given interval.

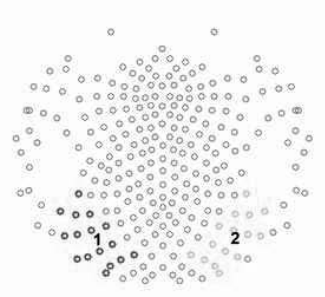

A)

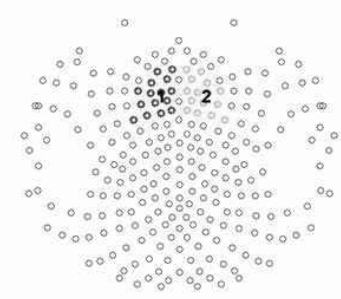

B)

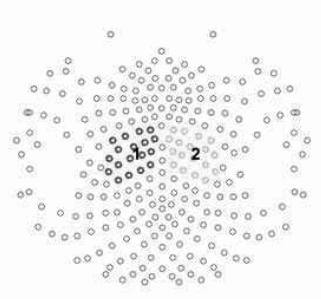

C)

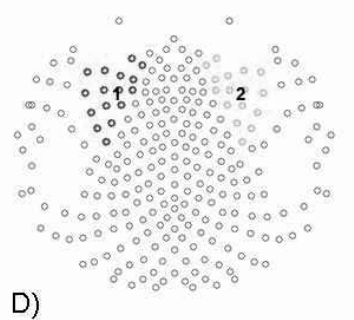

D)

(1)

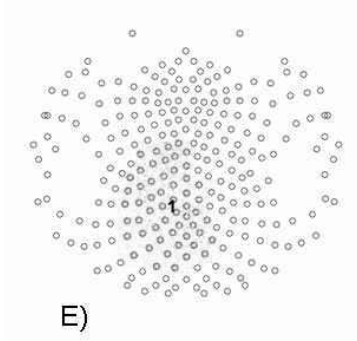

E)

Figure 2. Selected sensor groups for the analyzed ERP components. A: Left and right hemispheric sensor groups (16 sensors each) for N1 (150-200 ms) and EPN (200-300 $\mathrm{ms}$ ), all phases. B: Sensor groups for left and right frontal positivity during phase 2 (500-700 ms, 15 sensors each). C: Sensor group for left and right parietal LPP during phases 2 and 3 ( 18 sensors each). D: Sensor group for early frontal old/new effect (300$400 \mathrm{~ms}, 16$ sensors each) and E: Sensor group for late parietal old/new effect. (400-650 $\mathrm{ms}, 55$ sensors). [Colour online.]

Firstly, cortical processing of the stimuli was assessed comparing the encoding phase with the baseline phase. Secondly, the recognition phase was compared 
with the baseline phase, resulting in separate $2 \times 2$ repeated-measures ANOVAs with the factors: information content (negative, neutral) and phase (baseline versus encoding or baseline versus recognition) per sensor group. Where appropriate, laterality was also tested, in these cases resulting in a $2 \times 2 \times 2$ design with the additional factor sensor group (left, right).

Finally, old/new effects (negative, neutral, new) were calculated for parietal sites during the recognition phase. For each component, the repeated measures ANOVA contained the item status (negative, neutral, new) factor. Significant main or interaction effects containing more than two factor-levels were followed up using Fisher's LSD tests.

\section{Results}

\subsection{Recognition performance}

Behavioral data for recognition performance are shown in Table 1. Regarding effects of information content on recognition accuracy, differences for correctly recognized faces with negative versus neutral information indicated somewhat better recognition for faces with negative information, but the difference did not reach significance $[t(23)=1.71 ; p=0.101]$. After the first decision, the old $/$ new recognition revealed significantly more hits than false alarms $[t(23)=16.84 ; p<$ 0.001 ], indicating intact discrimination and non-random behavior.

The second decision between negative and neutral linguistic information included only the stimuli that participants had classified as old. Correctness of source assignment between faces with negative versus neutral information did not differ significantly $[t(23)=1.504 ; p=0.146]$.

Regarding reaction times during the old/new decision, hits revealed significantly shorter RTs than false alarms $[t(23)=-2.94 ; p<0.01]$. Hit RTs for correctly recognized faces differed in tendency between faces associated with negative and neutral information [ $\mathrm{t}(23)=-1.768, p=0.090]$, indicating somewhat shorter reaction times for faces with negative descriptions. During the second decision, concerning source memory and explicit recollection of associated information type, reaction times for faces with negative versus neutral information revealed significant differences for hits [ $\mathrm{t}(23)=-3.29 ; p<0.01]$. Results show significantly shorter RTs for source decisions on faces with negative descriptions, reflecting an emotion effect on the behavioral level. Results for reaction times are shown in Table 2. 
Table 1. Correct responses and false alarms with calculated standard errors for stimulus discrimination. Left: Recognition performance after first decision for old and new faces during the third phase. Right: Recognition performance after second decision for old faces with negative and neutral information during the third phase.

\begin{tabular}{|c|c|c|c|c|c|}
\hline \multicolumn{6}{|c|}{ Response rates [ms] } \\
\hline & \multicolumn{3}{|c|}{ After first decision } & \multicolumn{2}{|c|}{ After second decision } \\
\hline & Negative & Neutral & New & Negative & Neutral \\
\hline Correct response & 0.804 & 0.761 & 0.825 & 0.582 & 0.531 \\
\hline \multirow[t]{2}{*}{$\underline{\text { Standard Error }}$} & 0.032 & 0.030 & 0.034 & 0.039 & 0.032 \\
\hline & \multicolumn{2}{|c|}{ Old } & New & & \\
\hline Correct response & \multicolumn{2}{|c|}{0.783} & 0.825 & & \\
\hline Standard Error & \multicolumn{2}{|c|}{0.028} & 0.034 & & \\
\hline False alarm & \multicolumn{2}{|c|}{0.175} & & & \\
\hline Standard Error & \multicolumn{2}{|c|}{0.034} & & & \\
\hline
\end{tabular}

Table 2. Reaction times [ms] for correct responses and false alarms with calculated standard errors for stimulus discrimination. Left: Reaction time after first decision for old and new faces during the third phase. Right: Reaction time after second decision for old faces with negative and neutral information during the third phase.

\begin{tabular}{|c|c|c|c|c|c|}
\hline \multicolumn{6}{|l|}{ Reaction time [ms] } \\
\hline & \multicolumn{3}{|c|}{ After first decision } & \multicolumn{2}{|c|}{ After second decision } \\
\hline & Negative & Neutral & New & Negative & Neutral \\
\hline Correct response & 1398.1 & 1502.3 & 1356.6 & 1315.9 & 1508.1 \\
\hline \multirow[t]{2}{*}{$\underline{\text { Standard Error }}$} & 84.1 & 107.7 & 86.4 & 84.5 & 98.1 \\
\hline & \multicolumn{2}{|c|}{ Old } & New & & \\
\hline Correct response & \multicolumn{2}{|c|}{1450.2} & 1356.6 & & \\
\hline Standard Error & \multicolumn{2}{|c|}{92.0} & 86.4 & & \\
\hline False alarm & \multicolumn{2}{|c|}{1823.0} & & & \\
\hline Standard Error & \multicolumn{2}{|c|}{159.4} & & & \\
\hline
\end{tabular}

\subsection{EEG Data}

\subsubsection{Encoding phase versus baseline}

The RMS of face-evoked brain activity during baseline and encoding phases, which guided the selection of time windows of interest, is shown in Figure 3. 
N1: On the N1, an ANOVA with the factors phase (baseline, encoding), information content (negative, neutral), and laterality (left, right), revealed an effect of phase $[\mathrm{F}(1,23)=33.487, \mathrm{p}<.0001]$, a trend-level effect of sensor group $[\mathrm{F}(1,23)=3.725, \mathrm{p}=.066]$, and a marginal interaction of phase with laterality $[F(1,23)=3.692, p=.067]$. The effect of phase was due to the $\mathrm{N} 1$ being more negative during encoding than during baseline. The trend-level effect for sensor group was due to the ERP being somewhat more negative-going over the right than over the left hemisphere. The marginal interaction revealed that the lateralization effect arose primarily during encoding, where the amplitudes were larger over the right than the left hemisphere $(p<.0001)$. During baseline no hemispheric asymmetry was found $(\mathrm{p}=.25)$. No other main effects or interactions, including those involving information content, were significant (all $\mathrm{p} s>.1$ ).

EPN: An analogous ANOVA for the EPN revealed solely a main effect of phase $[F(1,23)=26.286, p<.001]$, the EPN being more negative during encoding than during baseline. No other main effects or interactions, including those involving information content, were significant (all ps $>.2$ ).

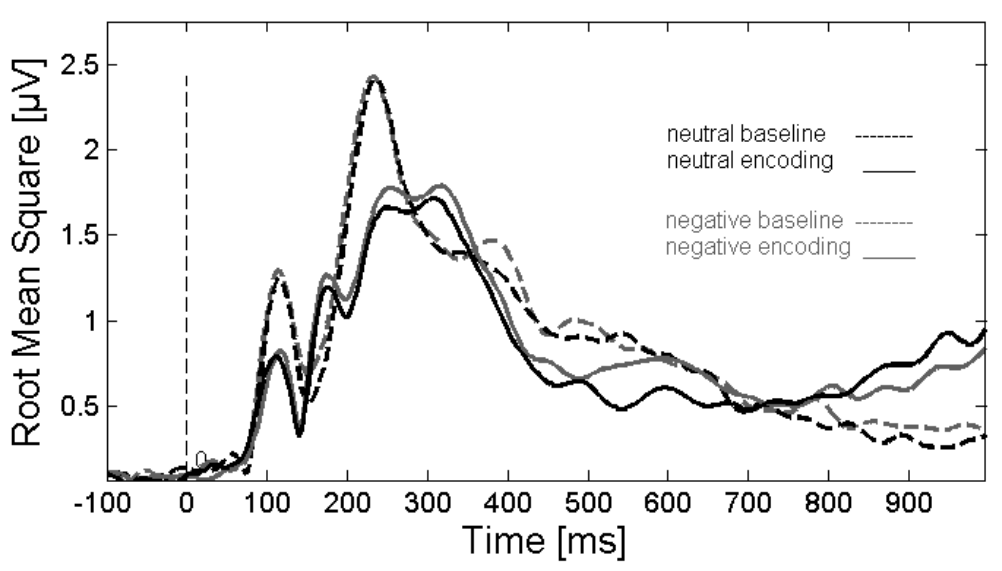

Figure 3. Time course of the root mean square (RMS) of face-evoked brain activity across all electrodes during baseline (dashed lines) and face encoding (solid lines) following language information (negative - red, neutral - black). [Colour online.]

LPP: Over frontal regions, a relative positivity emerged which was tested at two symmetrical frontal sensor groups. The test revealed a main effect of experimental phase $[F(1,23)=4.283, p=0.05]$ that was due to frontal ERPs being somewhat more positive-going during the encoding than during the baseline 
phase. More interestingly, an interaction between experimental phase, information content, and sensor group was found $[\mathrm{F}(1,23)=4.439, \mathrm{p}=0.046]$. This was due to the fact that over the left frontal group, a positivity emerged during encoding of negatively $(p<.05)$, but not neutrally $(p=.47)$ associated faces. Over the right frontal sensor group, for negatively associated faces the difference between baseline phase and encoding phase was absent $(p=.549)$, whereas over the right frontal group it was more pronounced for neutrally associated faces $(\mathrm{p}<.006)$.

None of the other main or interaction effects approached significance (all ps $>$.2).

A left centro-parietal positivity was also observed during encoding and its modulation was tested. However, here, none of the main or interaction effects was significant (all ps $>.15$ ).

For the interval from 500 to $700 \mathrm{~ms}$, the electrophysiological difference between encoding and baseline phases is shown in Figure 4.
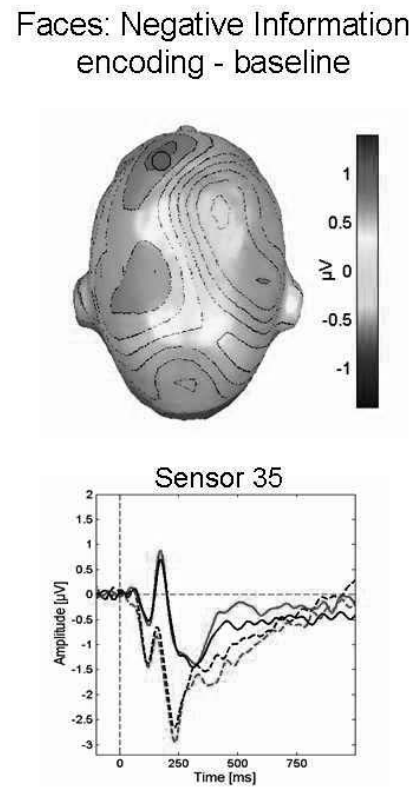
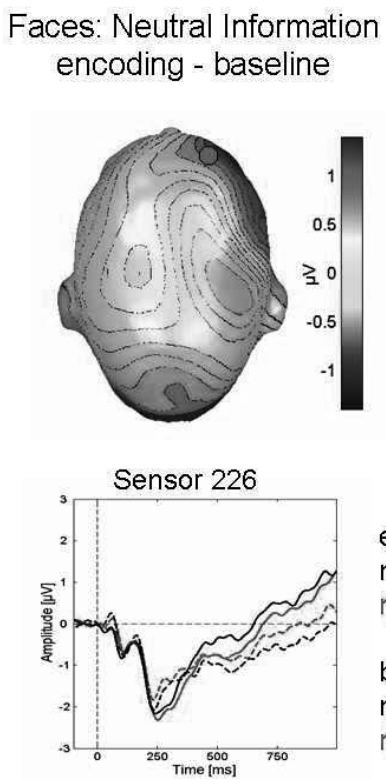

encoding:

neutral

negative

baseline:

neutral -.-.

negative --

Figure 4. Top row: Difference topography for event-related activity elicited during encoding of faces preceded by negative (top-left) and neutral (top-right) information in an interval from 500 to $700 \mathrm{~ms}$ after face onset. Bottom row: ERPs from two representative frontal sensors. Sensor position is marked with grey circles. [Colour online.] 


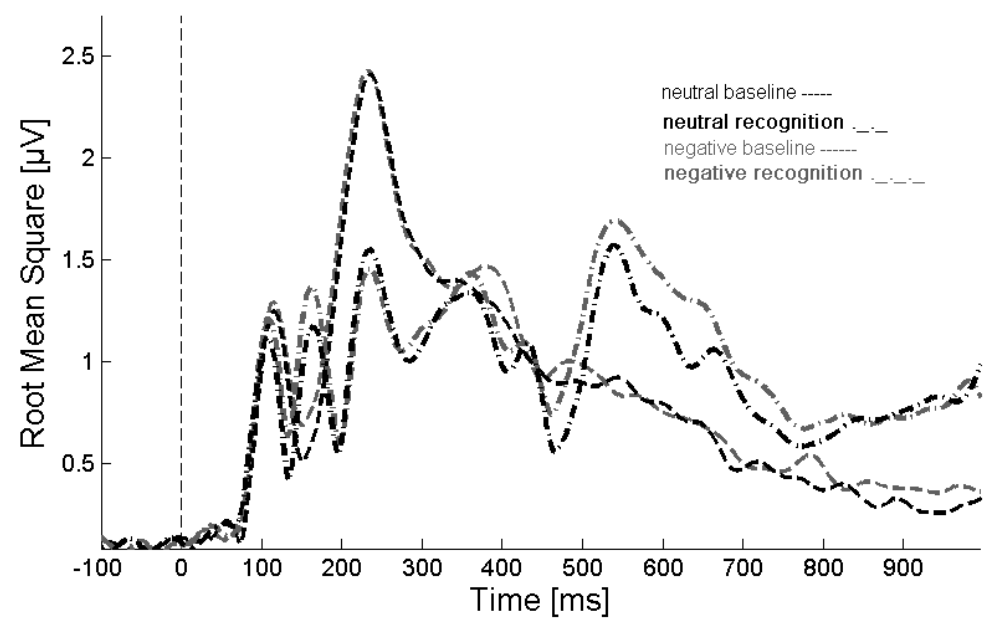

Figure 5. Time course of the root mean square of face-evoked brain activity across all electrodes during baseline (dashed lines) and face recognition (heavy dash-dot lines) of faces associated with negative (red) or neutral (black) language information. [Colour online.]

\subsubsection{Recognition phase versus baseline}

The RMS of face-evoked brain activity during baseline and recognition phases, which guided the selection of time windows of interest, is shown in Figure 5.

N1: An ANOVA with the factors phase (baseline, recognition), information content (negative, neutral), and laterality (left, right), revealed an effect of phase $[\mathrm{F}(1,23)=43.471, \mathrm{p}<.0001]$ and a trend-level interaction between phase and information content $[\mathrm{F}(1,23)=3.283, \mathrm{p}=.083]$. The effect of phase reflected that the $\mathrm{N} 1$ was more negative during recognition than during baseline and the trend-level interaction suggested that, in tendency, faces that would later be associated with neutral information had a higher N1 amplitude during baseline, whereas the reverse pattern appeared during recognition. However, upon pairwise comparison of faces during baseline and during recognition, both effects were clearly not significant ( $\mathrm{p}=.29$ and $\mathrm{p}=.47$, respectively). No other main effects or interactions, including those involving information content, were significant (all $\mathrm{ps}>.1$ ).

EPN: An ANOVA for the EPN revealed solely a main effect of phase $[\mathrm{F}(1$, $23)=23.795, p<.0001]$, the EPN being more negative during recognition than 
during baseline. No other main effects or interactions, including those involving information content, were found to be significant (all $\mathrm{p} s>.25$ ).

LPP: In the LPP window, between 460 and $660 \mathrm{~ms}$, a main effect of phase emerged $[F(1,23)=31.081, p<.0001]$, which reflected that ERPs during the recognition phase were more positive-going than during baseline. No main effects of information content and sensor group were found ( $\mathrm{ps}>.2$ ). Moreover, the two-way interaction between phase and sensor group was significant $[\mathrm{F}(1$, $23)=8.791, p<.005]$, indicating that the difference in activity between baseline and recognition phase was larger over the left $(p<.0001)$ than the right $(p<.05)$ hemisphere. The other two-way interactions were not significant $(\mathrm{ps}<.25)$. Most interestingly, a three-way interaction between experimental phase, information content, and sensor group was found $[\mathrm{F}(1,23)=9.487, \mathrm{p}=.005]$. This interaction reflected that over the left sensor group, there was a highly significant difference between negatively and neutrally associated faces during recognition $(\mathrm{p}<.001)$, whereas no such difference was found over the right sensor group $(\mathrm{p}=.44)$. Results for the recognition LPP are illustrated in Figure 6.
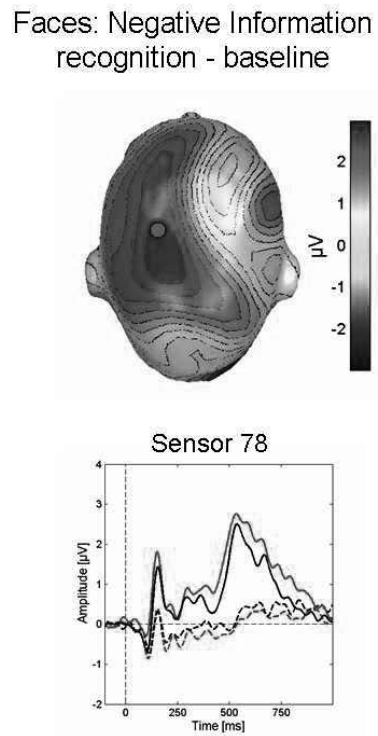

\section{Faces: Neutral Information recognition - baseline}
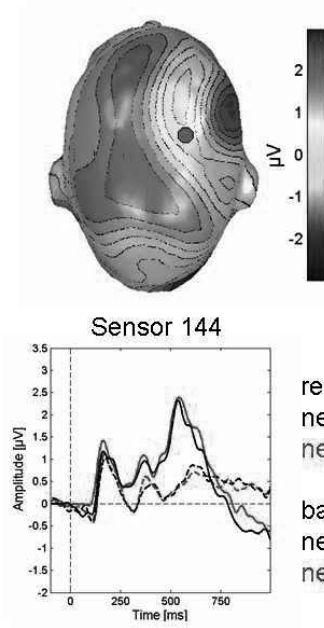

recognition:

neutral

negative

baseline: neutral ---negative -

Figure 6. Top row: Difference topography for event-related activity elicited during recognition of faces preceded by negative (top-left) and neutral (top-right) information in an interval from 460 to $660 \mathrm{~ms}$ after face onset. Bottom row: ERPs from two representative parietal sensors. Sensor position is marked with grey circles. [Colour online.] 


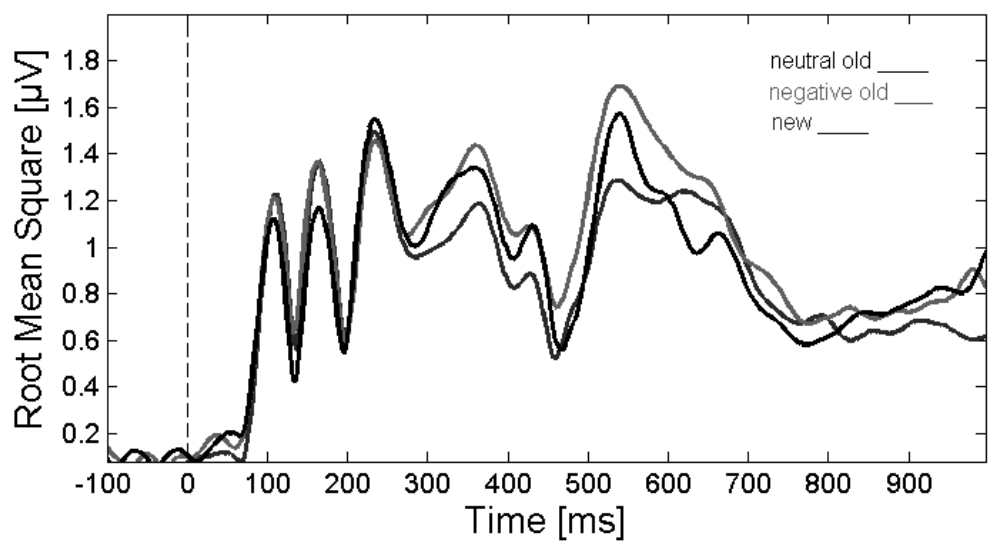

Figure 7. Time course of the root mean square of face-evoked brain activity across all electrodes for recognition of negatively (red) and neutrally associated (black), or new (blue) faces. [Colour online.]

\subsubsection{Old/New Effect}

The RMS of activity evoked during recognition of old negative and old neutral versus new faces is shown in Figure 7. Two potential time windows of interest emerge, an earlier one between 300 and $400 \mathrm{~ms}$, and a later one between 450 and $600 \mathrm{~ms}$.

Early Frontal Old/New Effect (300-400 ms): At fronto-lateral sensor groups, the early part of the old/new effect revealed a marginal effect of item status (negative association old, neutral association old, new, $[\mathrm{F}(2,46)=2.47, \mathrm{p}$ $=.095])$. The two sensor groups did not differ significantly $(\mathrm{p}>.5)$, nor was the interaction of item status and sensor group significant $(p>.5)$.

Because the difference topography suggested a parietal difference between old and new items already in this time window, this was also tested, but the effect was clearly not significant $(\mathrm{p}=.2)$.

Late Parietal Old/New Effect (450-600 ms): The parietal old/new effect between $450-600 \mathrm{~ms}$ was modulated by previous information $[\mathrm{F}(2,46)=4.412$, $\mathrm{p}<0.05]$. During recognition (third phase), the ERP was significantly more positive in response to negatively associated old items than the ERP to entirely new distractor faces $(\mathrm{p}=0.005)$. Neutrally associated old faces differed only in tendency from new faces $(p=0.078)$, although faces with negative and neutral as- 
sociations did not differ significantly $(\mathrm{p}=0.29)$. This content-modulated old $/$ new effect, which was significant for negatively but not for neutrally associated faces, was observed over extended posterior regions (see Figure 8).

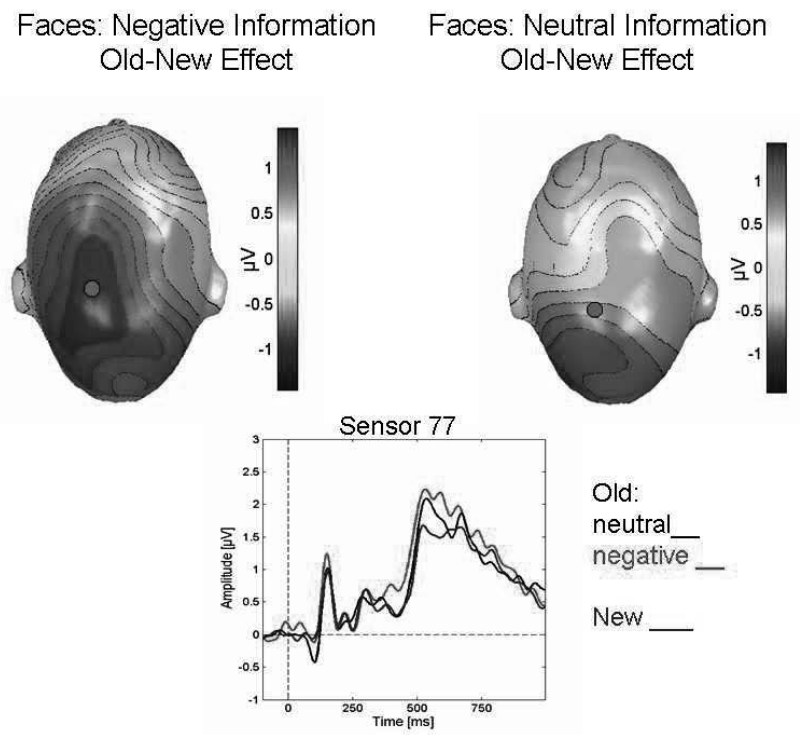

Figure 8. Top row: Difference topography for event-related activity elicited during recognition of faces preceded by negative (top-left) and neutral (top-right) information minus entirely new faces in an interval from 450 to $600 \mathrm{~ms}$ after face onset. Bottom row: ERPs from a representative parietal sensor. Sensor position is marked with grey circles. [Colour online.]

\section{Discussion}

In this study, we investigated the effect of preceding linguistic emotional information on subsequent encoding and recognition memory of faces with neutral expression. On the electrophysiological level, we found significant contentdriven modulations for frontal and centro-parietal late positive potentials as well as for the parietal old/new effect. No specific effects of emotional content were found for early perceptual processing stages (N1, EPN). Behaviorally, faces preceded by negative descriptions were recognized marginally more accurately 
than those preceded by neutral descriptions. However, source assignments were faster for negatively than for neutrally described faces.

Electrophysiology revealed an emotion-enhanced left-frontal relative positivity during encoding (second phase) for faces with negative versus neutral information, indicating an effect of emotional information during association formation. A conspicuous left centro-parietal positivity was only descriptively larger during encoding than during baseline. The more pronounced frontal effects during encoding may reflect the working memory load imposed by the present task, where descriptions had to be kept in mind and rehearsed before they could be associated with the face. A more positive-going frontal slow-wave might indicate easier integration of verbal information (Ruchkin et al. 1997). The observed lateralization difference might reflect hemispheric asymmetries in emotional processing (Grimshaw and Carmel 2014), but this could also have been caused by possible differences in the verbal material's imageability that were not explicitly assessed.

During the recognition phase, a theoretically expected left centro-parietal effect emerged as significant. It was larger for faces initially associated with negative rather than neutral information. EEG data from Abdel Rahman, MacNamara and colleagues, as well as from Maratos and colleagues support the present left central emotion LPP effects during recognition (Abdel Rahman 2011; MacNamara et al. 2011; Maratos et al. 2001a). Abdel Rahman found contextinduced emotion effects on the LPP for negative and positive versus neutral information during recognition of both famous and unknown faces some days after learning. For famous faces, emotional context effects occurred at both early (EPN) and late processing stages (LPP). For previously unknown faces, emotional context increased the LPP activation, but early ERP components were not modulated (Abdel Rahman 2011). MacNamara further showed audio contextinduced ERP parietal positivity effects for IAPS images that sustained about 30 min after initial pairing. Our data imply that these parietal effects of associated emotional information require an, albeit relatively brief, period of consolidation, as they are not that apparent during encoding, but quite sizeable during recognition which took place several minutes later.

In a similar vein, we also found the late parietal old/new effect to depend on a face's previous association. Similar to Schaefer et al.'s (2011) findings in recognition memory for emotional pictures, a parietal old/new effect was only significant when comparing negatively associated old with new faces, but not for the comparison of neutrally associated faces with new ones. The early frontal old/new effect, which typically reflects this effect's familiarity component, was also not significant, which is in line with the findings of earlier re- 
search (Weymar et al. 2009). Its absence might reflect the fact that faces had been presented three times before the recognition test and that linguistic information in association with each face had to be explicitly memorized. According to other studies, parietal activation seems to be crucial for recollection and corresponds with the given instructions (Rugg et al. 2007; Weymar et al. 2013). The present results are also compatible with the findings by Johansson and colleagues, who reported a larger parietal old/new effect for faces with negative than with positive or neutral expressions (Johansson et al. 2004). In this regard, our findings indicate that language information can induce similar neural effects in face recognition as intrinsic affective significance does. Regarding the mnemonic effects of language contexts, the current results are in line with Maratos and colleagues (Maratos et al. 2001a) and extend their results from effects of emotional language on neutral words embedded in emotional sentences to effects of emotional language on subsequently presented neutral faces.

The absence of a clearly significant old/new effect for neutral information is in line with Schaefer et al. (2011), although in their study a much longer retention interval of one week was used and the authors discuss their findings in terms of memory decay for neutral items. Here, by contrast, we used immediate testing and still obtained a similar pattern. The combined results of the two studies indicate that representation of neutral material may not only decay faster, as suggested by Schaefer and colleagues, but is also more difficult to establish than representation of emotional material, as evident from our data. The present stimuli were, by definition, structurally very similar and perhaps the verbal information for the neutral faces was not distinct enough to generate representations that differed reliably from that of other males with neutral expressions. Future studies should address issues of stimulus distinctiveness and test timing in more detail. Topographically, the present largely left-lateralized and centrally accentuated old/new effect for faces associated with negative information is very similar to the emotion enhancement of the old/new effect found in Weymar et al. (2009).

A lack of emotional information effects on early ERP components such as N1 and EPN in our study might be explained by the initially missing perceptual representations of facial stimuli or due to the encoding instruction that made all stimuli task-relevant, resulting in significant main effects of phase but not specific content for early components. Regarding the effect of verbal descriptions on subsequently presented IAPS pictures, MacNamara et al. likewise report no early ERP effects of information on subsequent perception. In contrast, Wieser et al. (2014) found EPN effects of both emotional sentence content and selfrelevance on subsequent face processing. Mid-latency components such as the 
EPN/N250 are modulated by the familiarity of faces (Tanaka et al. 2006), exhibiting larger amplitudes for familiar and famous faces compared to unknown ones (Herzmann et al. 2004). Thus, previously reported emotion effects at early (Landau et al. 2010; Righart et al. 2005) and mid-latency processing stages (Abdel Rahman 2011; Wieser et al. 2014) might have been at least partly due to pre-established familiarity of faces. Here, for the initially unknown faces, new representations had to be created first, and although a baseline phase established some degree of familiarity and amplitudes increased across repetitions, there was no modulation by the type of information presented. Finally, when using an explicit encoding design, preceding emotional language might generally affect late rather than early stages of the processing of new faces as, due to the instructions, all faces are equally perceptually relevant. Indeed, a recent magnetoencephalography study using the present materials in an evaluative conditioning paradigm, where information was presented auditorily simultaneously with the faces but without an explicit processing instructions, found mid-latency neural effects upon repeated presentation for passive viewing of the faces, but no very early or late effects (Junghöfer et al. 2016).

Despite the observed neural modulation by negative language, recognition accuracy of faces with negative and neutral information differed only in tendency. Similar results were found by Maratos and colleagues (Maratos et al. 2001a, $2001 \mathrm{~b}$ ) regarding effects of emotional language contexts, but also by Johansson et al. (2004) for faces with intrinsically emotional expressions. The lack of emotion-modulated recognition performance might be particularly due to brief consolidation time. Processing negative and neutral information in an explicit memory design requires explicit association and active retrieval of all material presented. Consolidation of emotionally arousing stimuli takes time and effects seem to increase for delayed retrieval. For instance, Sharot and Phelps found better recognition for emotionally arousing words after $24 \mathrm{~h}$ versus immediately, while recognition performance decreased for neutral words after a $24 \mathrm{~h}$ delay (Sharot and Phelps 2004). Overall, there appears to be a large inter-individual variability in emotion effects on memory that may be partly genetically mediated (De Quervain et al. 2007). In our study, as in many previous studies on memory, the negatively associated material is descriptively better recognized, but individual variability might impair significance. To compensate for individual differences, larger sample sizes of 30-40 participants would be useful for future studies. This might also reduce the possible effects of individual variability in perception of the valence of some of the descriptions used to induce emotional effects. Because there is a lack of truly neutral adjectives when it comes to social descriptions of people (see also Schindler et al. 2014), some of our occu- 
pation descriptions can be seen as positive, although overall valence ratings were clearly neutral. This fact may have attenuated some of the behavioral effects. On the neural level, positive content modulates recognition memory mostly via the familiarity-based frontal old/new effect (e.g. Kissler and Hauswald 2008; Schaefer et al. 2011) for which we did not find significant effects.

Regarding reaction times, significantly faster responses were found for the source assignment of faces associated with negative compared to neutral information, although this was not the case for the initial old/new decision. The latter may have been due to the delayed nature of the old/new response, which had to be withheld until face offset so as not to interfere with the face-evoked ERP. For the source assignment, by contrast, there was no such restriction and effects of emotional information occurred. According to Bradley and colleagues, who found fastest reaction times for old negatively arousing pictures in a delayed old/new recognition memory test, faster access to memories with emotional context is based on both better encoding and consolidation for arousing stimuli (Bradley et al. 1992). Abdel Rahman also found significantly shorter reaction times for faces previously paired with negative context (Abdel Rahman 2011). Our RT results indicate an emotional modulation of stimulus processing on the behavioral level. Apparently, in line with the higher salience of emotionally relevant material, memory search for negatively associated items is faster than for neutral ones. Future research needs to focus on the remaining discrepancies between neural and behavioral emotional effects. Using more varied encoding conditions (explicit versus implicit) and retention intervals as well as larger sample sizes seems most promising in this regard.

\section{In sum - Something always sticks?}

On the neural level, the results of the present study attest to the power of emotional language to modulate memory for perceptually neutral stimuli, in line with the view that language helps to construct emotion (Barrett et al. 2007) and establish explicit associative learning as one underlying mechanism. At the same time, our data also indicate that emotional language acts in a subtle and gradual manner and that its behavioral repercussions vary more than the neural ones do. Thus, the current emotionalization of language in the media may not have as profound direct behavioral effects as feared by some and hoped for by others. At the same time, there are many ways in which emotional language can affect cognition and behavior implicitly and explicitly. In the present study, its effects on explicit memory were less profound. However, a different study using 
the same materials in a passive evaluative conditioning paradigm found behavioral effects on face evaluation, which were mediated by both implicit and explicit learning (Junghöfer et al. 2016). The combined results underline that different mechanisms can mediate associative effects of emotional language on cognition. Thus, we are only beginning to understand the powers and limitations of verbal emotional information transmission that is so naturally and adeptly used in human communication.

\section{Acknowledgements}

The research was supported by a grant from the Deutsche Forschungsgemeinschaft (DFG KI1283/4-1). We thank Bettina Sutter for her help with data acquisition.

\section{REFERENCES}

Abdel Rahman, R. 2011. "Facing good and evil: Early brain signatures of affective biographical knowledge in face recognition". Emotion 11(6). 1397-1405.

Barrett, L.F., K.A. Lindquist and M. Gendron. 2007. 'Language as context for the perception of emotion“. Trends in cognitive sciences 11(8). 327-332.Blau, V.C., U. Maurer, N. Tottenham and B.D. McCandliss. 2007. "The face-specific N170 component is modulated by emotional facial expression”. Behavioral Brain Functions 3(7). 1-13.

Bradley, M.M., M.K. Greenwald, M.C. Petry and P.J. Lang. 1992. "Remembering pictures: pleasure and arousal in memory". Journal of experimental psychology: Learning, Memory, and Cognition 18(2). 379-390.

Bublatzky, F., and H.T. Schupp. 2011. "Pictures cueing threat: Brain dynamics in viewing explicitly instructed danger cues". Social cognitive and affective neuroscience 7(6). 611-22.

Bühler, K. 1934. Sprachtheorie: die Darstellungsfunktion der Sprache: mit 9 Abb. Im Text und auf 1 Tafel. Jena: Gustav Fischer Verlag.

Baayen, R.H., R. Piepenbrock and L. Gulikers. 1995. The CELEX lexical database (CDROM). Philadelphia, PA: Linguistic Data Consortium, University of Pennsylvania.

de Quervain, D.J., I.T. Kolassa, V. Ertl, P.L. Onyut, F. Neuner, T. Elbert and A. Papassotiropoulos. 2007. "A deletion variant of the $\alpha 2 \mathrm{~b}$-adrenoceptor is related to emotional memory in Europeans and Africans". Nature Neuroscience 10(9). 11371139. 
Dolcos, F. and R. Cabeza. 2002. "Event-related potentials of emotional memory: Encoding pleasant, unpleasant, and neutral pictures". Cognitive, Affective \& Behavioral Neuroscience 2(3). 252-263.

Eimer, M. and A. Holmes. 2007. "Event-related brain potential correlates of emotional face processing". Neuropsychologia 45(1). 15-31.

Ferree, T. C., P. Luu, G.S. Russell and D.M. Tucker. 2001. "Scalp electrode impedance, infection risk, and EEG data quality". Clinical Neurophysiology 112(3). 536-544.

Flaisch, T., F. Häcker, B. Renner and H.T. Schupp. 2011. "Emotion and the processing of symbolic gestures: an event-related brain potential study". Social cognitive and affective neuroscience 6(1). 109-118.

Grimshaw, G. M. and D. Carmel. 2014. "An asymmetric inhibition model of hemispheric differences in emotional processing". Frontiers in Psychology 5. 489. 1-7.

Herzmann, G., S.R. Schweinberger, W. Sommer, and I. Jentzsch. 2004. "What's special about personally familiar faces? A multimodal approach". Psychophysiology, 41(5). 688-701.

Ille, N., P. Berg and M. Scherg. 2002. "Artifact correction of the ongoing EEG using spatial filters based on artifact and brain signal topographies". Journal of Clinical Neurophysiology 19(2). 113-24.

Johansson, M., A. Mecklinger and A.C. Treese. 2004. "Recognition memory for emotional and neutral faces: An Event-Related Potential study". Journal of Cognitive Neuroscience 16(10). 1840-1853.

Junghöfer, M., and P. Peyk. 2004. "Analysis of electrical potentials and magnetic fields of the brain". Matlab Select 2. 24-28.

Junghöfer, M., M.A. Rehbein, J. Maitzen, S. Schindler and J. Kissler. 2016. “An evil face?-Verbal evaluative Multi-CS conditioning enhances face-evoked mid-latency magnetoencephalographic responses". Social Cognitive and Affective Neuroscience, nsw179.

Kensinger, E.A. and S. Corkin. 2003. "Memory enhancement for emotional words: Are emotional words more vividly remembered than neutral words?" Memory \& Cognition 31(8). 1169-1180.

Kissler, J., R. Assadollahi and C. Herbert. 2006. "Emotional and semantic networks in visual word processing - insights from ERP studies". Progress in Brain Research 156. 147-184.

Kissler, J., C. Herbert, P. Peyk and M. Junghöfer. 2007. '”Buzzwords'- Early cortical responses to emotional words". Psychological Science 18(6). 475-80.

Kissler, J. and A. Hauswald. 2008. "Neuromagnetic activity during recognition of emotional pictures". Brain Topography 20(4). 192-204.

Kissler, J., C. Herbert, I. Winkler and M. Junghöfer. 2009. "Emotion and attention in visual word processing - An ERP study". Biological Psychology 80(1). 75-83.

Landau, A.L., L. Aziz-Zadeh and R.B. Ivry. 2010. "The Influence of Language on Perception: Listing to Sentences about Faces Affects the Perception of Faces". The Journal of Neuroscience 30(45). 15254-15261.

MacNamara, A., D. Foti and G. Hajcak. 2009. 'Tell me about it: Neural activity elicited by emotional pictures and preceding descriptions". Emotion 9(4). 531-543. 
MacNamara, A., K.N. Ochsner and G. Hajcak. 2011. "Previously reappraised: the lasting effect of description type on picture-elicited electrocortical activity". Social, Cognitive and Affective Neuroscience 6. 348-358.

Maratos, E.J. and M.D. Rugg. 2001a. "Electrophysiological correlates of the retrieval of emotional and non-emotional context". Journal of Cognitive Neuroscience 13(7). 877-891.

Maratos, E.J., R.J. Dolan, J.S. Morris, R.N.A. Henson, and M.D. Rugg. 2001b. "Neural activity associated with episodic memory for emotional context". Neuropsychologia 39. 910-920.

Mather, M.and M/R. Sutherland. 2011. “Arousal-biased competition in perception and memory”. Perspectives on Psychological Science 6(2). 114-133.

Mattarozzi, K., A. Todorov and M. Codispoti. 2014. "Memory for faces: the effect of facial appearance and the context in which the face is encountered". Psychological Research 79(2). 308-317.

Mignault, A. and A. Chaudhuri. 2003. "The many faces of a neutral face: Head tilt and perception of dominance and emotion". Journal of Nonverbal Behavior 27(2). 111132.

Olofsson, J.K., S. Nordin, H. Sequeira and J. Polich. 2008. "Affective picture processing: an integrative review of ERP findings". Biological psychology 77(3). 247 265.

Pastor, M.C., M.M. Bradley, A. Löw, F. Versace, J. Moltó and J.P. Lang.2008. “Affective picture perception: emotion, context, and the late positive potential". Brain research 1189. 145-151.

Righart, R. and B. de Gelder. 2005. "Context influences early perceptual analysis of faces - An electrophysiological study". Cerebral Cortex 16. 1249-1257.

Righi, S., T. Marzi, M. Toscani, S. Baldassi, S. Ottonello and M.P. Viggiano. 2012. "Fearful expressions enhance recognition memory: electrophysiological evidence". Acta psychologica 139(1). 7-18.

Rugg, M.D. and T. Curran. 2007. "Event-related potentials and recognition memory". Trends in Cognitive Sciences 11(6). 251-257.

Ruchkin, D. S., R.S. Berndt, R. Johnson, W. Ritter, J. Grafman and H.L. Canoune. 1997. "Modality-specific processing streams in verbal working memory: evidence from spatio-temporal patterns of brain activity“. Cognitive Brain Research 6(2). 95-113.

Sands, S.F. 2009. Sample size analysis for brainwave collection (EEG) methodologies. White Paper.

Sato, W., T. Kochiyama, S. Yoshikawa and M. Matsumura. 2001. "Emotional expression boosts early visual processing of the face: ERP recording and its decomposition by independent component analysis". Neuroreport 12. 709-714.

Schaefer, A., K. Fletcher, C.L. Pottage, K. Alexander and C. Brown. 2009. "The effects of emotional intensity on ERP correlates of recognition memory". Neuroreport 20(3). 319-324.

Schaefer, A., C.L. Pottage and A.J. Rickart. 2011. "Electrophysiological correlates of remembering emotional pictures". Neuroimage 54(1). 714-724.

Schindler, S., M. Wegrzyn, I. Steppacher and J. Kissler. 2014. "It's all in your headhow anticipating evaluation affects the processing of emotional trait adjectives". Frontiers in psychology 5. 1292. 1-10. 
Schupp, H.T., B.N. Cuthbert, M.M. Bradley, J.T. Cacioppo, T. Ito and P.J. Lang. 2000. "Affective picture processing: The late positive potential is modulated by motivational relevance". Psychophysiology 37. 257-261.

Schupp, H.T., M. Junghöfer, A.I. Weike and A.O. Hamm. 2003. "Emotional facilitation of sensory processing in the visual cortex". Psychological Science 14. 7-13.

Schupp, H.T., M. Junghöfer, A.I. Weike and A.O. Hamm. 2004a. "The selective processing of briefly presented affective pictures: An ERP analysis". Psychophysiology 41. 441-449.

Schupp, H.T., A. Öhman, M. Junghöfer, A.I. Weike, J. Stockburger and A.O. Hamm. 2004b. "The facilitated processing of threatening faces: An ERP analysis". Emotion 4. 189-200.

Sharot, T.and E.A. Phelps. 2004. "How arousal modulates memory: disentangling the effects of attention and retention". Cognitive, Affective \& Behavioral Neuroscience 4(3). 294-306.

Tanaka, J.W., T. Curran, A.L. Porterfield and D. Collins. 2006. "Activation of preexisting and acquired face representations: The N250 event-related potential as an index of face familiarity". Journal of Cognitive Neuroscience 18(9). 1488-1497.

Tottenham, N., J.W. Tanaka, A.C. Leon, T. McCarry, M. Nurse, T.A. Hare, D.J. Marcus, A. Westerlund and C. Nelson. 2009. "The NimStim set of facial expressions: Judgments from untrained research participants". Psychiatry Research 168(3). 242-249.

Weymar, M., A. Löw, C.A. Melzig and A.O. Hamm. 2009. "Enhanced long-term recollection for emotional pictures: Evidence from high density ERPs". Psychophysiology 46(6). 1200-1207.

Weymar, M., M.M. Bradley, A.O. Hamm and P.J. Lang. 2013. "When fear forms memories: Threat of shock and brain potentials during encoding and recognition". Cortex 49(3). 819-826.

Wieser, M.J., A. Gerdes, I Büngel, K.A. Schwarz,A. Mühlberger and P. Pauli. 2014. "Not so harmless anymore: How context impacts the perception and electrocortical processing of neutral faces". NeuroImage 92. 74-82.

\author{
Address correspondence to: \\ Johanna Kissler \\ Department of Psychology \\ University of Bielefeld \\ PO Box 100131 \\ D-33501 Bielefeld \\ Germany \\ johanna.kissler@uni-bielefeld.de
}




\section{APPENDIX}

\section{Linguistic stimulus material}

\section{Negative context - 30 descriptions}

Dieser asoziale Kidnapper hat ein Baby verschleppt.

This anti-social kidnapper abducted a baby.

Dieser krankhafte Amokläufer hat Studenten erschlagen.

This pathological spree killer slayed students.

Dieser perverse Sexualtäter hat ein Kind geschändet.

This perverse sex-offender defiled a child.

Dieser hinterhältige Verbrecher hat einen Mann ertränkt.

This devious villain drowned a man.

Dieser abstoßende Vergewaltiger hat Frauen missbraucht.

This abhorrent rapist abused women.

Dieser schäbige Kriminelle hat einen Studenten ermordet.

This mean criminal murdered students.

Dieser heuchlerische Dealer hat Männer abgestochen.

This two-faced dealer stabbed men.

Dieser kaltblütige Häftling hat einen Menschen erwürgt.

This cold-blooded prisoner strangled people.

Dieser bestialische Zuhälter hat eine Frau hingerichtet.

This bestial pimp executed a woman.

Dieser arrogante Schläger hat einen Mitarbeiter gequält.

This arrogant thug tortured an employee.

Dieser grauenvolle Peiniger hat eine Studentin vergewaltigt.

This horrible tormentor raped a student.

Dieses erbarmungslose Monstrum hat Kinder misshandelt.

This merciless monster abused children.

Dieser grausame Schlächter hat Menschen verstümmelt.

This cruel slaughterer mutilated people.

Dieser korrupte Gangster hat Passanten abgeschlachtet.

This corrupt gangster slaughtered pedestrians.

Dieser fanatische Terrorist hat Passagiere niedergestochen.

This fanatic terrorist stabbed passengers.

Dieser kriminelle Angeklagte hat Touristen erschossen.

This criminal defendant shot tourists.

Dieser rücksichtslose Straftäter hat Babies vergiftet.

This reckless offender poisoned babies.

Dieser teuflische Bombenleger hat Mitarbeiter getötet.

This evil bomb planter killed employees.

Diese selbstherrliche Bestie hat eine Nachbarin ertränkt.

This egomaniac beast drowned a neighbor.

Dieser verhasste Schwerverbrecher hat Mädchen umgebracht.

This detested felon killed girls. 
Dieser unheilbare Gefangene hat Nachbarn niedergeschlagen.

This cureless captive defeated neighbors.

Dieser zwanghafte Serienmörder hat einen Freund erstochen.

This obsessive serial killer stabbed a friend.

Dieser widerliche Kinderschänder hat ein Mädchen gefoltert.

This disgusting child abuser tortured a girl.

Dieser scheußliche Gewalttäter hat einen Schüler erhängt.

This horrible criminal hanged a student.

Dieser verwahrloste Henker hat einen Jungen erstickt.

This shabby executioner choked a boy.

Dieser hässliche Menschenhändler hat Schüler entführt.

This ugly slave trader kidnapped students.

Dieses herablassende Biest hat eine Freundin stranguliert.

This patronizing beast strangled a friend.

Dieser entstellte Killer hat eine Schülerin niedergeschossen.

This blemished killer shot a student.

Dieser ekelhafte Kannibale hat Jungen niedergemetzelt.

This disgusting man-eater slaughtered boys.

Dieser ätzende Wiederholungstäter hat Freunde erdrosselt.

This awful recidivist strangled friends.

\section{Neutral context -30 descriptions}

Dieser progressive Chemiker hat einen Impfstoff hergestellt.

This progressive chemist produced a vaccine.

Dieser objektive Biologe hat einen Nadelbaum untersucht.

This objective biologist investigated a coniferous tree.

Dieser zerstreute Geologe hat Gesteinsproben analysiert.

This absent-minded geologist analyzed rock samples.

Dieser sentimentale Archäologe hat Denkmäler ausgegraben.

This sentimental archeologist excavated monuments.

Dieser revolutionäre Astronom hat einen Stern entdeckt.

This revolutionary astronomer discovered a star.

Dieser heroische Facharzt hat Heilmethoden entwickelt.

This heroic specialist developed cures.

Dieser disziplinierte Optiker hat Sehstörungen erforscht.

This disciplined optician explored visual disorders.

Dieser verklärte Philosoph hat eine Theorie verworfen.

This misty-eyed philosopher rejected a theory.

Dieser zaghafte Psychologe hat Entspannung empfohlen.

This cautious psychologist recommends relaxation.

Dieser fromme Theologe hat ein Kirchenfest veranstaltet.

This pious theologian hosted a church festival.

Dieser verwegene Detektiv hat Beweismaterial überprüft.

This venturous detective reviewed evidence.

Dieser listige Bauleiter hat eine Genehmigung beantragt. 
This artful construction supervisor requested a permit. Dieser gönnerhafte Makler hat Wohnungen vermietet. This patronizing real estate agent let apartments.

Dieser berechenbare Notar hat Urkunden beglaubigt. This predictable solicitor authenticated the documents. Dieser subjektive Redakteur hat Eilmeldungen gedruckt. This subjective editor printed breaking news.

Dieser verschmitzte Buchhändler hat Zeitschriften verkauft. This mischievous bookseller sold magazines.

Dieser selbstlose Tierpfleger hat ein Jungtier aufgezogen.

This altruistic zookeeper reared a young animal.

Dieser schweigsame Imker hat einen Bienenstock beobachtet.

This silent beekeeper watched a beehive.

Dieser impulsive Hausmeister hat eine Leitung kontrolliert.

This impulsive janitor checked the power line.

Dieser gefällige Briefträger hat Paketwaren geliefert.

This compliant postman delivered packages.

Dieser versonnene Gärtner hat eine Rosenart gezüchtet.

This pensive gardener grew a variety of roses.

Dieser häusliche Bäcker hat eine Teigmischung produziert.

This domestic baker produced a mix of dough.

Dieser eigenwillige Fleischer hat Schweinefilets geschnitten.

This headstrong butcher cut pork fillets.

Dieser bürgerliche Landwirt hat Süßkartoffeln geerntet.

This civil farmer picked sweet potatoes.

Dieser lautlose Dachdecker hat eine Solaranlage montiert.

This silent roofer installed a solar collector.

Dieser konventionelle Tischler hat Möbelstücke angefertigt.

This conventional carpenter manufactured furniture.

Dieser unverschuldete Schlosser hat ein Stahlgerüst aufgebaut.

This innocent locksmith constructed a steel framework.

Dieser rigorose Klempner hat Rohrabschnitte verlegt.

This rigorous plumber laid pipe sections.

Dieser bedenkenlose Mechaniker hat eine Ölheizung repariert.

This unhesitating mechanic repaired oil heating.

Dieser unerfahrene Elektriker hat eine Stromquelle installiert.

This inexperienced electrician installed a power source. 